\title{
Effect of Polymer's Type and Content on Tensile Strength of Polymers Modified Asphalt Mixes
}

\author{
Ghufraan Mohammed Aboud ${ }^{a *}$, Nabil Habib Jassem a, Teba Tariq Khaled a, Azaldeen Ali \\ Abdulhussein ${ }^{a}$, Vikas Kumar ${ }^{b}$ \\ ${ }^{a}$ Highway and Transportation Engineering Department, Mustansiriyah University, Baghdad, Iraq \\ ${ }^{b}$ Civil and Construction Engineering Department, Oregon State University, Oregon, USA
}

\section{ARTICLE INFO}

Article history:

Received 21 November 2019

Received in revised form 12 January 2020

Accepted 23 January 2020

\section{Keywords:}

Asphalt mixtures

Polyvinyl Chloride (PVC)

Natural Rubber (NR)

Mechanical Characteristics

\begin{abstract}
A B S T R A C T
There has been a considerable rise in road traffic in the past twenty years due to the fast-pace development of the country. In addition, the inadequate and less frequent maintenance exacerbated the deterioration of road structure. This increase in traffic volume combined with the harsh climatic environment of Iraq causes early signs of distress such as low-temperature cracking, rutting, and fatigue cracking. Polymers obtained from the local sources or recycled additive from other sources have been used in pavements to improve their performance as well as to make them more sustainable. This paper presents a laboratory evaluations that were used to determine mechanical characteristics and performance of asphalt mixtures with different types of additives such as (Polyvinyl Chloride (PVC) and Natural Rubber (NR)) and various content. The modified asphalt mixtures were prepared with asphalt binder previously modified by using four percentages of polymer $(2,4,6$, and $8 \%)$ from the weight of asphalt binder. Many tests were conducted to evaluate mixtures performance such as (the volumetric properties, mechanical characteristics, indirect tensile strength (ITS) test, and double punching shear (DPS)). The results indicated that the PVC polymer and natural rubber improved the performance of the mixtures compared to the control mixture.
\end{abstract}

\section{Introduction}

Over the past 20 years in Iraq, the increase in road traffic with inadequate and less frequent maintenance exacerbated the deterioration of asphalt pavements. Cracking and rutting are major structural distress that was led to a reduction in the serviceability of asphalt pavements. This is serving as a major problem for the local authorities and policymakers. Therefore, it is important to evaluate the cracking, rutting and mechanical characteristics of the asphalt mixtures to improve its performance against rutting and fatigue cracking. Therefore, sorts of additives and modifiers are employed in asphalt to reduce the distresses effect. Polymers additives in asphalt pavements are a method of imparting additional durability to HMA mixture, allowing to improve the pavement performance against the distresses. However, in the asphaltic pavement industry has used many additives over the past decades to improve pavement performance. A polymer commonly is one of the additives to asphalt that can improve thermal cracking and fatigue low resistance, low-temperature condition, skid resistance, and rutting resistance (( e.g. styrene-butadiene-styrene (SBS), styrene-butadiene (SB), styrene-butadiene rubber (SBR), and styrene-isoprene-styrene (SIS)) and plastomers (e.g. polyethylene (PE),

* Corresponding author.

E-mail address: ghufraaneng2014@gmail.com (ghufraan mohammed aboud) 
$P \quad$ the peak or the maximum load

$D$ diameter of the sample

T height or thickness of sample

\section{$\sigma_{t} \quad$ Punching shear stress \\ $p \quad$ Maximum or peak load \\ a Punch's radius \\ $b \quad$ Radius of sample. \\ $h \quad$ Height of sample}

ethylene-vinyl acetate (EVA), and polypropylene (PP)) [1-3]. Many researchers investigated and evaluated the performance and the material design of Polymer-reinforced asphalt mixture [4-6] conducted a study to study the impact of different types of polymer on rutting resistance. The results indicated that NR mixtures were most resistant from the other mixtures concerning rutting. Nobinur Rahman et al. [7] was used two types of additives polyethylene and PVC to evaluate asphalt properties by using Marshall mix design. Tests were conducted to determine voids, stability, and unit weight. The authors found that polyethylene gave a better result than PVC. Polyvinyl Chloride (PVC) can be used in asphalt pavements by adding them to asphalt binders by $10 \%$ and $7.5 \%$ from the total weight respectively [7]. A lot of researchers studied the evaluation and impact of plastic waste in asphalt mixtures and their performance. All results indicated that using plastic waste in asphalt mixes exhibits improvement in their engineering properties such as flow, moisture-resistance, resistance to crack propagation, and Marshall stability [8-11]. [12] was focused in his study on the rheological properties of modified binders with SBS, styrenebutadiene-styrene (SBS), ground tire rubber (GTR), or polyphosphoric acid (PPA) and the results referred to the modifiers have insignificant effect at low temperatures. In addition, the results indicated that the performance of pure binder in high temperatures can be improved by adding the (PVC and NR) and other additives.

\section{Aim of the Study}

In this paper, fieldwork was conducted at Iraqi capital Baghdad to identify the common asphalt problems and improve pavement performance. The main objectives of this study are to: (i) find the influence of different types of polymers (PVC and NR) on the performance of hot mix asphalt and mechanical characteristics. (ii) Reduce cracking by obtaining softer blends. (iii) Reduce rutting by reaching blends at high temperatures. (iv) Increase the strength and the stability of mixtures.

\section{Materials and Methodology}

\subsection{Aggregates}

In this study, the aggregate was obtained from Al-Nibaee quarry close to Baghdad city. Its size ranges between passing sieve $(19 \mathrm{~mm})$ and retained on sieve $(4.75 \mathrm{~mm})$ in accordance with (S.C.R.B. 2003) [13]. Two types of fine aggregates were used in this study; they were crushed aggregates and sand aggregate. The fine aggregates were range between passing the sieve $(4.75 \mathrm{~mm})$ and retaining on the sieve $(0.075 \mathrm{~mm})$. Therefore, the aggregate gradation employed in this study was followed the middle point gradation as shown in the Iraqi specification for Hot Mix Asphalt (surface layer) and Fig. 1. The aggregates properties are shown below in Table 1.

\subsection{Bituminous Materials}

The asphalt (40/50) penetration grade was used in this investigation; it was obtained from the Daurah refinery in Baghdad. The asphalt binder properties were evaluated as per the AASHTO routine tests. The physical properties of this grade of the asphalt binder are given in Table 2.

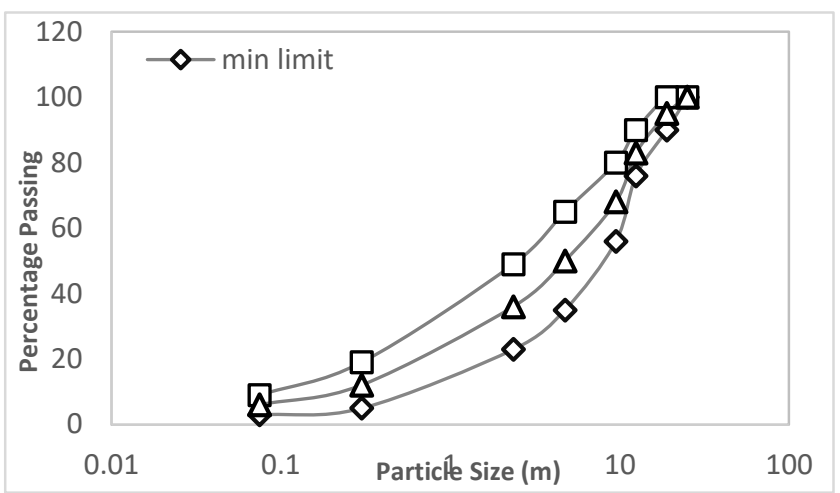

Figure 1. Aggregate Gradation Used in the Study

Table 1. Aggregate properties

\begin{tabular}{lllll}
\hline \multirow{2}{*}{ Property } & \multicolumn{2}{l}{ Coarse Aggregate } & \multicolumn{2}{l}{ Fine Aggregate } \\
\cline { 2 - 5 } & ASTM 2010 & Result & ASTM 2010 & Result \\
Bulk Specific Gravity & C-127 & 2.603 & C-128 & 2.651 \\
Apparent Specific Gravity & C-127 & 2.658 & C-128 & 2.692 \\
Percent Water Absorption & C-127 & 0.453 & C-128 & 0.733 \\
Loss Angels Abrasion & C-131 & 18.3 & ----- & ----- \\
\hline
\end{tabular}

Table 2. Properties of used bituminous binder

\begin{tabular}{ll}
\hline Property & Test Results \\
\hline Penetration & 43 \\
Kinematic Viscosity & 390 \\
Softening Point & 51.5 \\
Ductility & $>100$ \\
Flash Point & 335 \\
Specific Gravity & 1.048 \\
Loss on heat & 0.18 \\
\hline
\end{tabular}

\subsection{Filler}

Portland cement bought from Al-Taji cement manufactory was used as filler in this work. The bulk specific gravity of the cement was 3.4 $\left(\mathrm{gm} / \mathrm{cm}^{3}\right)$. Table 3 shows the ordinary Portland cement filler properties.

\section{Table 3. Physical Properties of Portland cement}

\begin{tabular}{ll}
\hline \multicolumn{1}{c}{ Property } & Cement \\
\hline Specific Surface & 3372 \\
Bulk sp. gr & 3.4 \\
$\%$ Passing No. 200 & 96 \\
\hline
\end{tabular}

\subsection{Additives}

The selection of polymer type should have durability, good adhesion, and availability. In this research, two types of polymer were selected: Poly vinyl 
chloride (PVC), and natural rubber (NR). The researchers collected the polymers from the market.

\subsection{Marshall Specimen Preparation}

Samples with a diameter $(101.6 \mathrm{~mm})$ and approximately $(63.5 \mathrm{~mm})$ height were prepared in the laboratory to study the Marshall stability of asphaltic mixtures with different types and contents of additives (PVC and NR). Marshall Mixture design method was utilized to arrive at the optimum binder content as per Iraqi specification (SORB,2003), and the methodology used for this design is ASTM, 2003 [14]. Therefore, the weight of aggregates and mineral fillers were $(1200 \mathrm{gm})$ and mixed, and the temperature mixing was near to $\left(160^{\circ} \mathrm{C}-180^{\circ} \mathrm{C}\right)$. Marshall Method was utilized to design the hot asphalt mixtures. Hence, the samples are required to be mixed and compacted under equivalent to the temperature corresponding to viscosities of $(0.170 \pm 0.02)$ Pas.sec and $(0.280 \pm 0.03)$ Pas.sec, respectively [15]. The Rotational Viscometer has been adopted for determining the viscosity of asphalt cement at temperatures (above $100 \mathrm{C}^{\circ}$ ) to ensure that the asphalt cement is adequate fluid for pumping and mixing. Brookfield Rheometer was used to measure the viscosity at two temperatures $\left(135 \mathrm{C}^{\circ}\right)$, and $\left(165 \mathrm{C}^{\circ}\right)$ for each asphalt binder type according to (ASTM D-4402 [16] and AASHTO T- 316 [17]). Table 4 shows the values of mixing and compacting temperatures for the asphalt cement mixing with different percentages of additives. This study, different contents of bitumen were used to determine the optimum bitumen content for the pure bitumen, which it was (4.9\%), and the O.C.A. for the additive and percent of content shown in Table 5. The percentages of polymer (PVC and NR) were $(2,4,6$, and $8 \%$ ) from the weight of asphalt, which was used in this work. At $\left(165^{\circ} \mathrm{C}\right)$ the mixing equipment and specimen molds were also placed in the oven. The number of specimens prepared in this study was 60 specimens and compacting with 75 blows on each side of the specimen. The number of specimens which was used to test the indirect tensile was (20) specimen and used (20) specimen to test the double punching as shown in Fig. 2 and Fig. 3.

Table 4. Mixing and Compacting Temperature

\begin{tabular}{lllll}
\hline \multirow{2}{*}{ Additive } & \multicolumn{2}{c}{ PVC } & \multicolumn{2}{c}{ NR } \\
& $\begin{array}{l}\text { Mixing } \\
\text { Temp. }\end{array}$ & $\begin{array}{l}\text { Compacting } \\
\text { Temp. }\end{array}$ & $\begin{array}{l}\text { Mixing } \\
\text { Temp. }\end{array}$ & $\begin{array}{l}\text { Compacting } \\
\text { Temp. }\end{array}$ \\
\hline $\mathbf{2 \%}$ & 163 & 153 & 161 & 153 \\
$\mathbf{4 \%}$ & 166 & 157 & 165 & 155 \\
$\mathbf{6 \%}$ & 170 & 161 & 168 & 159 \\
$\mathbf{8 \%}$ & 175 & 164 & 171 & 162 \\
\hline
\end{tabular}

Table 5. asphalt content and Rotational Viscosity (ASTM D4402)

\begin{tabular}{|c|c|c|c|c|}
\hline \multirow[b]{2}{*}{ Additive } & \multicolumn{2}{|c|}{ PVC } & \multicolumn{2}{|c|}{ NR } \\
\hline & O.C.A & $\begin{array}{l}\text { Rotational } \\
\text { viscosity at } \\
135 c^{\circ}\end{array}$ & O.C.A & $\begin{array}{l}\text { Rotational } \\
\text { viscosity at } \\
135 \mathrm{c}^{\circ}\end{array}$ \\
\hline $2 \%$ & 4.9 & 0.14 & 4.9 & 0.132 \\
\hline $4 \%$ & 5.1 & 0.15 & 5.0 & 0.146 \\
\hline $6 \%$ & 5.4 & 0.17 & 5.3 & 0.17 \\
\hline $8 \%$ & 5.5 & 0.19 & 5.6 & 0.1862 \\
\hline
\end{tabular}

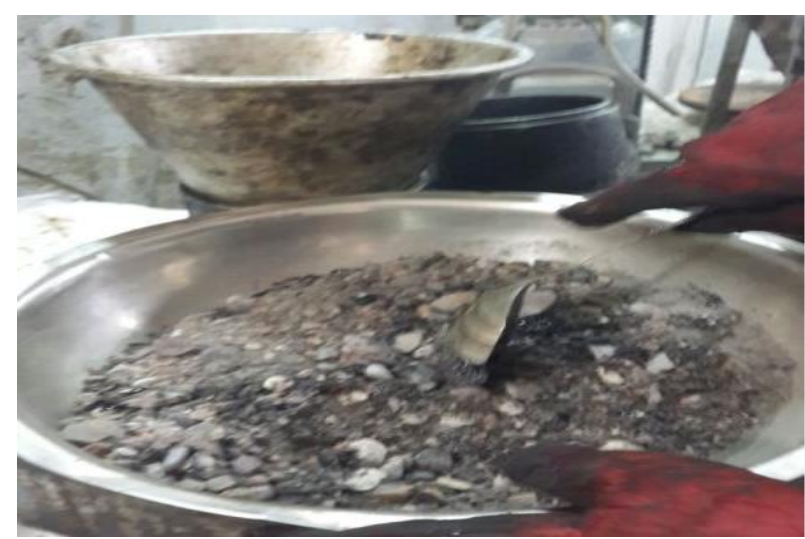

Figure 2. Shows the Specimens Prepared.

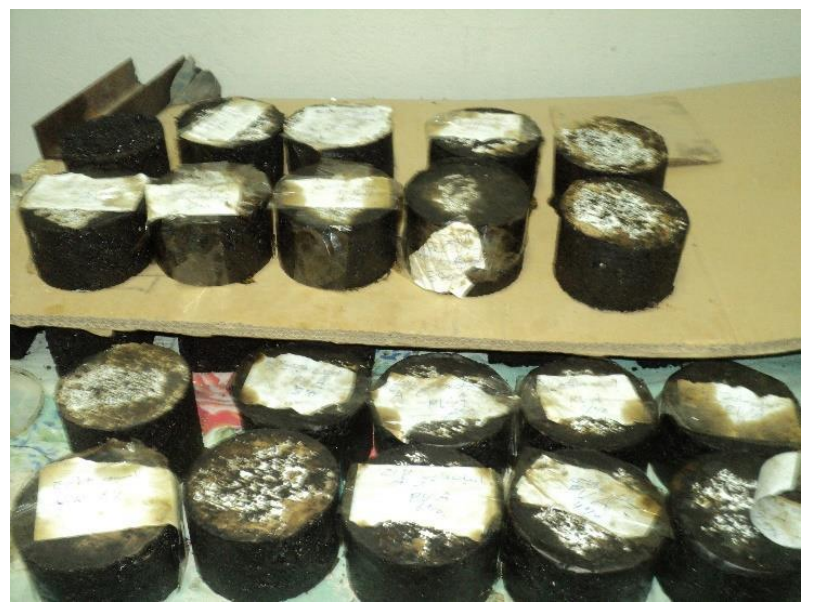

Figure 3. The Specimens Prepared.

\section{Experimental Test}

\subsection{Indirect Tension Strength (ITS) Test}

In the investigation, tensile properties of the asphalt mixtures are determined by using the ITS according to ASTM D 6931[16]. The test gives information on tensile strength and fatigue characteristics. ITS test involves placing the cylindrical sample along the diametrical axis. A constant deformation rate of $5.1 \mathrm{~cm} / \mathrm{min}$ is applied to the specimens until failure by splitting along the vertical diameter at $25^{\circ} \mathrm{C}$ as shown in Fig. 4 and Fig. 5. The indirect tensile strength of each sample was determined according to the following equation:

$$
\mathrm{ITS}=\frac{2 \mathrm{P}}{\pi \mathrm{Dt}}
$$

Where:

$\mathrm{P}=$ the peak or the maximum load in $\mathrm{KN}$

$\mathrm{D}=$ diameter of the sample in $\mathrm{cm}$

$\mathrm{T}=$ height or thickness of sample in $\mathrm{cm}$ 


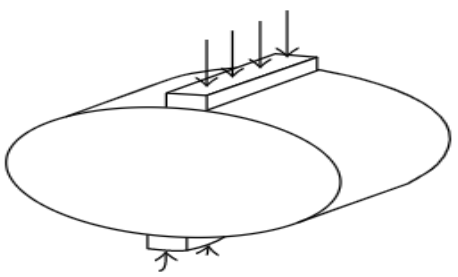

(a) Load configuration

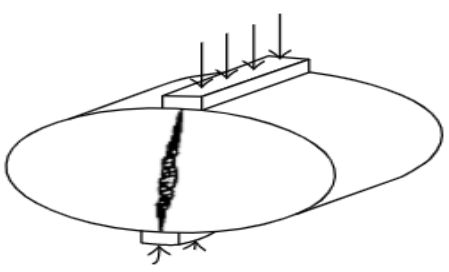

(b) Failure of specimen

Figure 4 ITS Test Loading and Failure Mechanism Process.

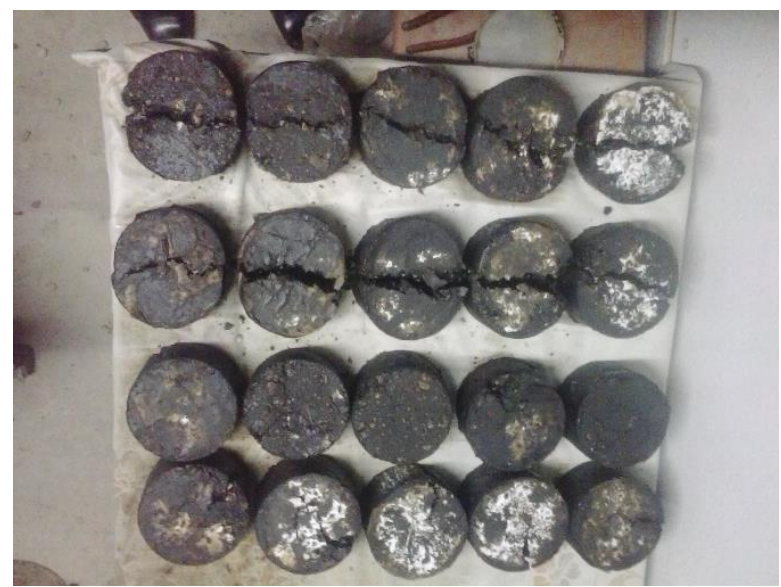

Figure 5. Specimens after ITS Test.

\subsection{Double Punching Test}

This test was reported by many studies. A double punching test was used to measure the stripping of the binder from the aggregate according to Jimenez [18]. Conditioning of the samples was done by placing them in water bath for $30 \mathrm{~min}$ at $60^{\circ} \mathrm{C}$ and Marshall was used to prepare the samples as shown in Fig. 6. The loading Piston was placed on the highest associated bottom faces of the specimens and have a diameter of one in $(25.4 \mathrm{~mm})$ and the load was applied at a constant rate of $0.1 \mathrm{in.} / \mathrm{min}$ until failure. The tensile strength was computed by adopting the equation developed by Chen [19] as follows:

$$
\sigma_{t}=\frac{p}{\pi\left(1.2 b h-a^{2}\right)}
$$

where:

$\sigma_{t}=$ Punching shear stress in $\mathrm{Pa}$

$p=$ Maximum or peak load in $\mathrm{N}$.

$a=$ Punch's radius in $\mathrm{mm}$.

$b=$ Radius of sample in $\mathrm{mm}$.

$h=$ Height of sample in $\mathrm{mm}$.

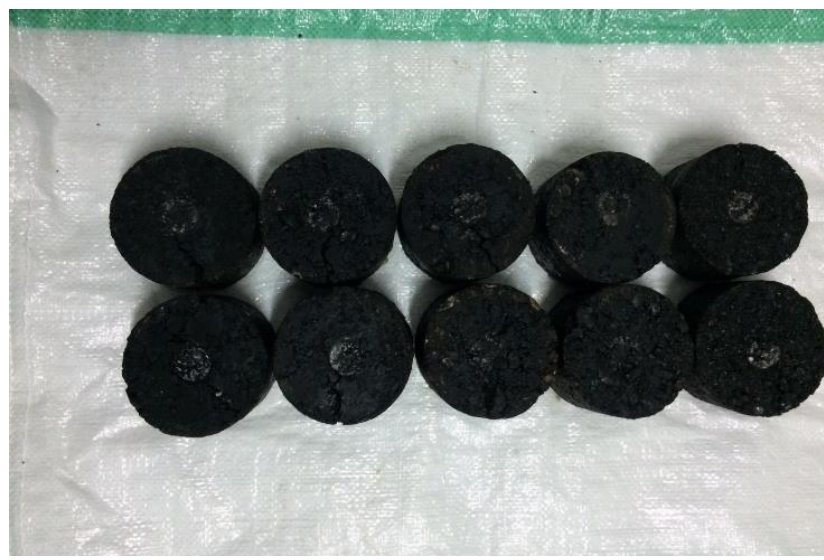

Figure 6. Specimens after Double Punching Test.

\section{Results and Discussion}

\subsection{Effect of Polymers and Polymer Content on ITS and Punching Strength}

The indirect tensile strength test was employed to determine the tensile properties of asphalt mixtures. The tensile properties can, in turn, be related to cracking properties of the asphalt pavement. In this study, all the asphalt specimens were tested at the same temperature to avoid any difference in their properties during their preparation or testing. Therefore, the tensile test indicates the overall strength of the asphalt mixture as a response to the repetition of loads or fatigue loading. Higher the strength obtained from ITS test, higher is the fatigue resistance of the mixture. The values of ITS at $25^{\circ} \mathrm{C}$ for the modified asphalt mixtures with the trial percentages of the polymers are presented in Fig. 7. From the output of ITS test, the tensile strength for the control mixture is $(950 \mathrm{kN})$ and these values increase with the increasing percentage of polymer until a specific percentage and then decrease. However, it can be observed that the asphalt mixture modified with (4\%) of PVC polymer has the highest indirect tensile strength and with the NR has a minimum indirect tensile strength at the same percentage. At higher percentage $(>4 \%)$, the tensile strength of the PVC polymer modified asphalt (PMA) decreases. In addition, the indirect tensile test for the (6\%) NR polymer, provide the maximum load strength and the indirect tensile test for the (6\%) PVC polymer also gives an acceptable load strength and deformation. It can be said that the (6\%) PVC and NR Polymer content is the optimum Polymer content (O.P.C) for the ITS test. The strength of PMA in both these cases is considerably higher than the control mixture. When the polymer is added to the mixture, it is noted that the ITS increases more than the control mixture. This is related to the fact that polymer content gives more stiffness than the control mixture and is mainly due to the higher viscosity of asphalt binder when used polymer.

On the other hands, the double punch test gives a mainly indicates the stripping behavior between binder and aggregate. Double punch test results were proved that the mixtures, which contain the different percentage of polymers gives the performed well compared with the control mixture. Fig.8 shows the impacted of double punching by increasing the polymers in hot asphalt mixture and concludes that the punching strength value for mixtures which contain PVC and NR are increased with the increasing percentage of polymers content. This might is related to the stiffness of mixtures, which is lower in the control mixture and higher in the PVC and NR mixtures. From the chart, it can be concluded that out of all the 
additives, NR shows a drastic improvement in the punching strength of the mixtures compared to the control mixture and mixtures, which contain different percentages of (PVC). The control mixture and mixtures with (2\%) and (4\%) of PVC and (NR) have similar punching strength values approximately. The double punching strength with $(6 \%)$ from PVC and NR give a performed well in both the tests and therefore, can be termed as the optimum polymer content (O.P.C).

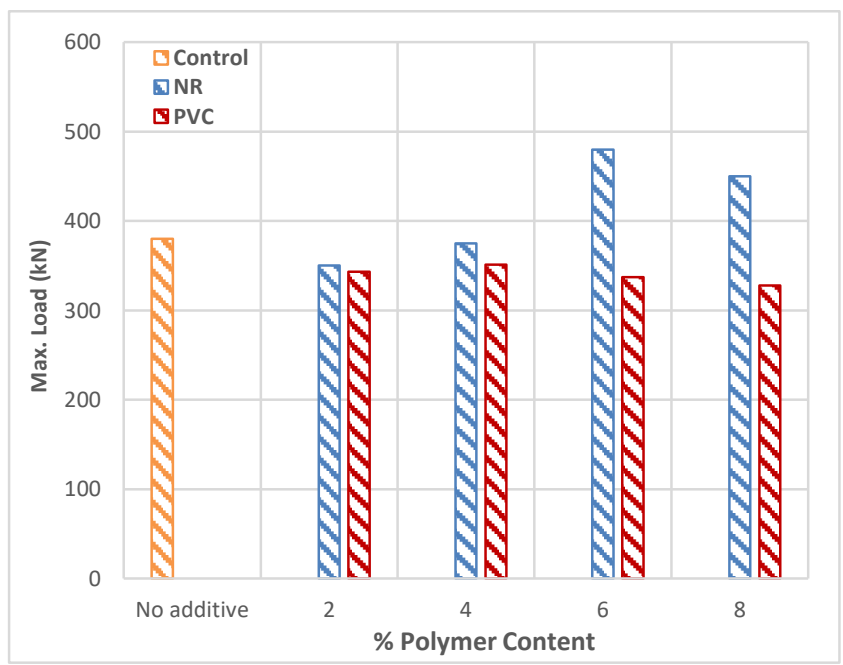

Figure 7. Indirect Tensile Strength for Different Polymer Content in the Mixtures.

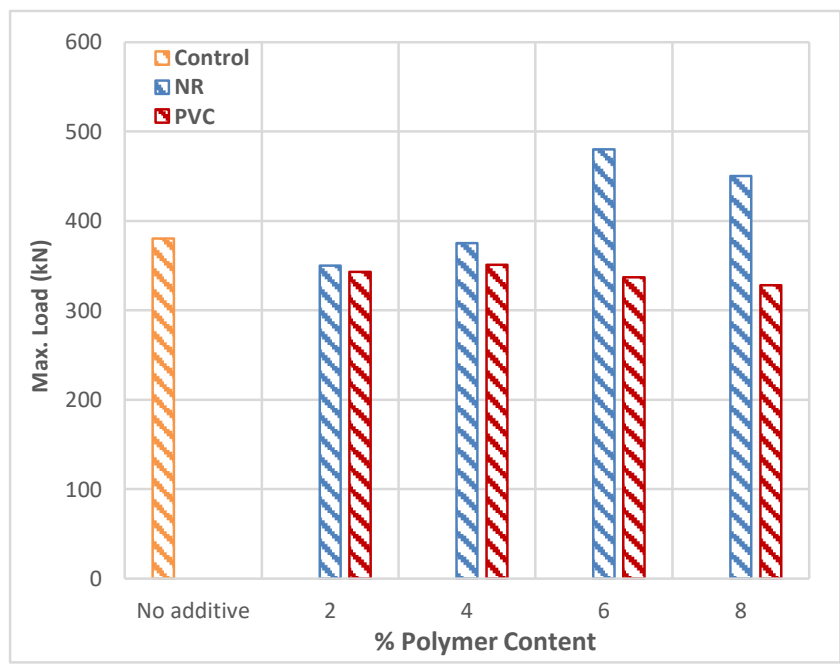

Figure 8. Punching Strength for Different Polymer Content in the Mixtures.

\subsection{Effect of Polymer Modified Asphalt on Deformation}

The deformation results obtained from the ITS test for all the mixtures with different percentage of polymers are shown in Fig. 9. The results correspond to the test carried out at the rate of $0.05 \mathrm{in} / \mathrm{min}$ by using the master loader device. From the results, it is evident that $(2 \%)$ of PVC, modified asphalt mixture has a strength of $(3963 \mathrm{~N})$ for $(2 \mathrm{~mm})$ deformation. and this strength is comparable to the strengths of NR mixture with $4 \%$ and $6 \%$ polymer content. The ideal content from (PVC) and (NR) polymers that can improve the resistance to deformation is (6\%) compared to the control mixture. Because add the PVC or NR to the asphalt binder led to make the mixture hardness and that was increased with increasing the percentages of additive content which cases to reduction in the ability of the mixture to carry the load applied. Therefore, all of the above due to reducing the ability to carry the deformations.

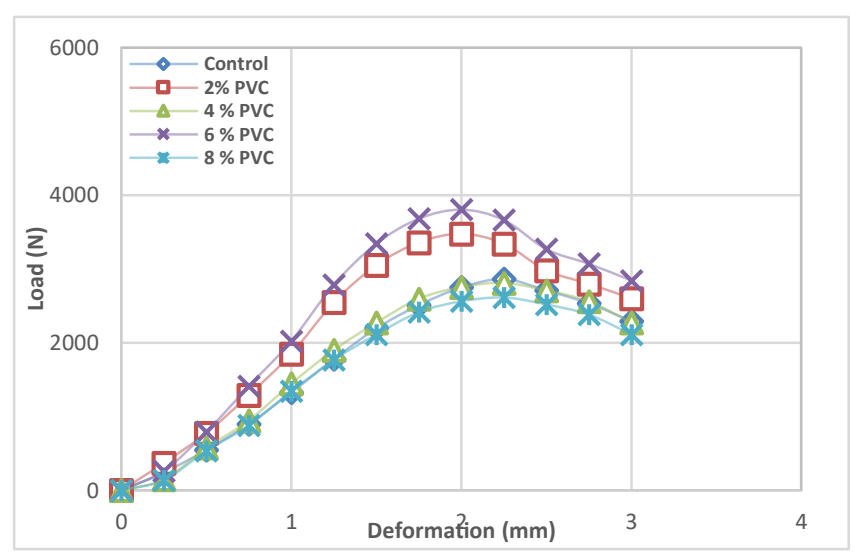

(a)

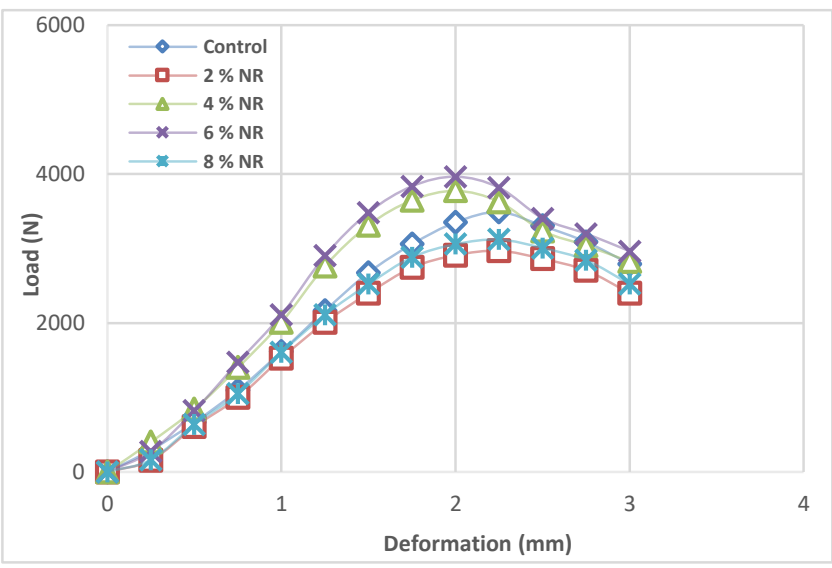

(b)

Figure 5. From a to b Load-Deformation Relationship for Different Polymer Content in the Mixtures.

\section{Conclusion}

The principal objective of this study was to investigate the mechanical performance of modified asphalt mixtures with different types of additives (PVC and NR). The study included conducting laboratory tests on bitumen and mixtures with polymers content. Also, mechanistic and simulative tests were conducted on modified and unmodified asphalt concrete mixtures (ITS and DPT test). After analyzing the data, the results indicated that:

- $\quad$ The addition of PVC and NR in the asphalt mixtures led to improve the quality and strength of the asphalt mixture, it is showed by increasing the indirect tensile strength for the specimens prepared for that.

- It was noted that the PVC and NR increased from the shear resistance among asphalt binder and aggregates and that may be related to increasing the stiffness of the asphalt mixture. 
- The asphalt mixtures with the polymer-modified asphalt proven adequate to cracking resistance.

- The optimum polymer content between all the different percentage of polymers used in this experiment $(2 \%, 4 \%, 6 \%$ and $8 \%)$ in the asphalt mixture from (PVC) and (NR) is the $(6 \%)$.

- $\quad$ The ideal content of polymers from (PVC) and (NR) that can improve from the resistance to deformation is $(6 \%)$ compared to the control mix i.e. HMA mix without polymers.

\section{Acknowledgment}

The authors would like to express their deepest gratitude to Mustansiriyah University for providing support, and also to the transportation and highway engineering department at Al- Mustansiriyah University for the technical support for this study.

\section{REFERENCES}

[1] J. Zhu, B. Birgisson, N.J.E.P.J. Kringos, Polymer modification of bitumen: Advances and challenges, 54 (2014) 18-38.

[2] J.-S. Chen, M.-C. Liao, H.-H.J.P.F.A. Tsai, Evaluation and optimization of the engineering properties of polymer-modified asphalt, 2(3) (2002) 75-83.

[3] Y.J.C. Yildirim, B. Materials, Polymer modified asphalt binders, 21(1) (2007) 6672.

[4] S. Tayfur, H. Ozen, A.J.C. Aksoy, B. Materials, Investigation of rutting performance of asphalt mixtures containing polymer modifiers, 21(2) (2007) 328-337.

[5] G.J.J.o.M.S. Airey, Styrene butadiene styrene polymer modification of road bitumens, 39(3) (2004) 951-959.
[6] M.R.S. Fernandes, M.M.C. Forte, L.F.M.J.M.r. Leite, Rheological evaluation of polymer-modified asphalt binders, 11(3) (2008) 381-386.

[7] M.N. Rahman, M. Ahmeduzzaman, M. Sobhan, T.J.A.J.o.C.E. Ahmed, Architecture, Performance evaluation of waste polyethylene and PVC on hot asphalt mixtures, 1(5) (2013) 97-102.

[8] V. Swami, A. Jirge, K. Patil, S. Patil, S. Patil, K.J.I.J.o.E.S. Salokhe, Technology, Use of waste plastic in construction of bituminous road, 4(5) (2012)

[9] A.M. Abu Abdo, M.E. Khater, Enhancing rutting resistance of asphalt binder by adding plastic waste, Cogent Engineering, 5(1) (2018).

[10] M.A.J.J.I.J.o.A.o.I.i.E. Chavan, Management, Use of plastic waste in flexible pavements, 2(4) (2013) 540-552.

[11] A. Gawandea, G. Zamarea, V. Rengea, S. Taydea, G. Bharsakaleb, AN OVERVIEW ON WASTE PLASTIC UTILIZATION IN ASPHALTING OF ROADS.

[12] A. Behnood, J.J.C. Olek, B. Materials, Rheological properties of asphalt binders modified with styrene-butadiene-styrene (SBS), ground tire rubber (GTR), or polyphosphoric acid (PPA), 151 (2017) 464-478.

[13] S.C.R.B. , IRAQI General Specifications for Roads \& Bridges 20032003.

[14] A. ASTM, Standard test method for resistance to plastic flow of bituminous mixtures using Marshall apparatus, (2000).

[15] S.M.J.A.I. Design, Lexington, Ky, Superpave Series No. 2 (SP-2), (1996).

[16] D. ASTM, Standard test method for viscosity determination of asphalt at elevated temperatures using a rotational viscometer, in: American Society for Testing and Materials, 2015.

[17] A.A.o.S. Highway, T. Officials, Standard Specifications for Transportation Materials and Methods of Sampling and Testing and AASHTO Provisional Standards, American Association of State Highway and Transportation Officials, 2016.

[18] R. Jimenez, Testing for debonding of asphalt from aggregates, (1973).

[19] W. Chen, Double punch test for tensile strength of concrete, Sept. 1969 (70-18) PB224770/AS (NTIS), (1969). 